Álvares, J.S. and Costa, D.B. (2018). "Literature review on visual construction progress monitoring using Unmanned Aerial Vehicles". In: Proc. 26 th Annual Conference of the International. Group for Lean Construction (IGLC), González, V.A. (ed.), Chennai, India, pp. 669-680. DOI: doi.org/10.24928/2018/0310. Available at: www.iglc.net.

\title{
LITERATURE REVIEW ON VISUAL CONSTRUCTION PROGRESS MONITORING USING UNMANNED AERIAL VEHICLES
}

\author{
Juliana S. Álvares ${ }^{1}$, and Dayana B. Costa ${ }^{2}$
}

\begin{abstract}
Due to the complexity and dynamism that characterize construction activities, the execution of work packages as planned requires a systematic monitoring and control of their operations and progress. However, the most common practices for construction progress monitoring are still based on individual observations and often still rely on textbased documentation. In order to improve the collaboration and transparency of this process, studies highlight applications of visual data, such as photographs, videos, 3D and 4D models. Due to the large number of publications that address the use of visual data for construction progress monitoring, and the growing use of Unmanned Aerial Vehicles (UAVs), the objective of this work is to present a systematic literature review concerning the use of UAVs as a tool for aiding construction progress monitoring. For that purpose, a literature review was carried out for papers dated from 2008 to 2018 using Scopus database. The findings indicated that the development of progress monitoring automated systems, the use of 3D as-built point cloud models and Building Information Modeling are the most frequently discussed subjects within the papers surveyed. Also, a gap was identified regarding the lack of studies that effectively integrate the visual monitoring with the construction management systems.
\end{abstract}

\section{KEYWORDS}

Construction progress monitoring, Visual data, Unmanned Aerial Vehicles/Systems (UAVs/UASs).

\section{INTRODUCTION}

The activity of work progress monitoring and controlling is one of the fundamental tasks for an efficient management of the construction process (Del Pico, 2013).Del Pico (2013)

1 Civil Engineer, Master's Student, Graduate Program in Civil Engineering, Federal University of Bahia (UFBA), Brazil, alvares.juliana@ hotmail.com.

2 Associate Professor, Engineering School, Department of Structural and Construction Engineering, Graduate Program in Civil Engineering, Federal University of Bahia (UFBA), Brazil, dayanabcosta@ufba.br. 
defines the process of progress monitoring and controlling as a series of established steps and metrics that aim to evaluate and compare current performance against planned performance, identifying variances/deviations (differences between as-planned and asbuilt). Ballard (2000) states that for effective monitoring and control, negative variances should be mitigated by implementing corrective actions (necessary to keep production aligned with planning).

However, according to Teizer (2015), the most common practices for monitoring construction progress are still based on frequent individual observations and often still rely on textual documentation that require intensive and time-consuming data collection, analysis, updating, review and reporting. In order to improve this process, studies highlight the use of visual data (photographs, videos, 3D and 4D models) as solutions that simplify and optimize the progress monitoring, reducing the number of steps and parties involved and the time spent interpreting work status. Thus, this facilitates analysis of potential delays in production and improves the implementation of corrective actions (Golparvar-Fard et al., 2009; Han and Golparvar-Fard, 2015; Teizer, 2015).

The use of visual technologies in construction can reduce the non-value adding, costly and time-consuming activities associated with the progress monitoring process, mainly in regards to the as-built model creation that can be visualized and automated to a certain degree (Tezel and Aziz, 2017). This visualisation and automation can decrease the number of mistakes made in those routine tasks. Thus, the outcomes related to higher visualization and process transparency reducing the amount of non-value adding activities and minimizing defects are very much associated with Lean Construction principles (Sacks et al., 2010).

Lin and Golparvar-Fard (2017) comment that the use of site realistic visual data and the superimposition and comparison of those data with visual representations of planning (using Building Information Modelling- BIM, for instance) corroborates for an integrated visual management of planning and control tasks and production performance in a more transparent and collaborative way. Such visual technologies have the potential to improve the information flow of communication, comprehension, evaluation and application of corrective actions of construction progress (Han et al., 2018; Lin and Golparvar-Fard, 2017; Tezel and Aziz, 2017).

Therefore, the most common tools used for recording visual data on construction sites include digital cameras and devices with integrated cameras, such as smart phones, tablets, terrestrial and aerial unmanned vehicles, as well as laser scanning devices (Han and Golparvar-Fard, 2017; Han et al., 2018). Among these, Unmanned Aerial Vehicles (UAVs) have distinguished themselves for their advantages.

The advancement of Unmanned Aerial Vehicle technology, especially related to the small UAVs and those operated by rotary propeller systems associated with attached sensors, such as high resolution digital cameras and GPS, makes it a reliable tool and easy-to-operate on construction sites for visual data recording (Han et al., 2018; Han and Golparvar-Fard, 2015; McCabe et al., 2017).By enabling fast and complete construction site images capture from different positioning, the potential of UAVs to monitor and document construction progress has been explored in recent studies(Lin et al., 2015; McCabe et al., 2017). 
In view of the large number of publications that address the use of visual data for construction progress monitoring and the growinguse of UAVs for recording the work status, the main goal of this study is to present a systematic literature reviewaiming to discuss the use of UAVs to aid construction progress monitoring. This study attempts to bring to light the current state of this subject, taking into account the main recurrent or relevant specific issues discussed and how the studies address the use of UAVs specifically.

\section{RESEARCH METHOD}

This study consists of a literature review of relevant publications related to the topics addressed. The scientific database chosen was the Scopus of Elsevier, because it represents one of the most wide-ranging abstracts and citations database from publications in journals and conference proceedings. According to Elsevier (2016), Scopus covers over 5000 international journals, and papers from more than 83,000 events.

Two systematic literature reviews were carried out. The first was related to use of visual data for construction progress monitoring, and the second addressed the use of UAVs to aid construction progress monitoring. In both searches, the filter options of Article title, Abstract, and Keywords were used.

\section{LITERATURE REVIEW 1: USE OF VISUAL DATA FOR CONSTRUCTION PROGRESS MONITORING}

For the first literature search, the following combination of terms was used: Construction "progress monitoring" and Visual. In addition, only papers from 2008 onwards and the ones published in consolidated journals were considered. Figure 1 shows the step-by-step structure adopted for literaturesearch1 on Scopus database.

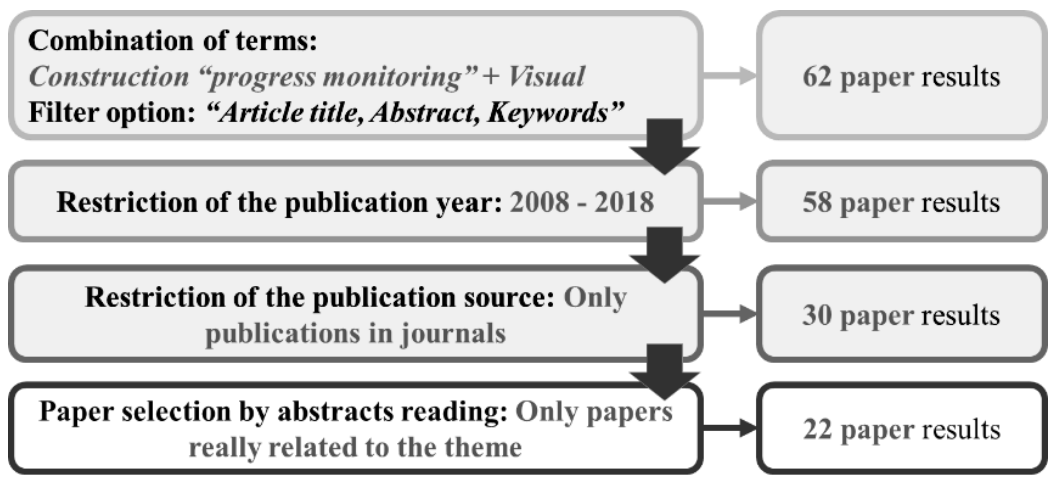

Figure 1:Step-by-step of the literature search 1

From the 22 papers selected, the following analyses were carried out:

- Quantitative distributions: number of papers published per journal and number of papers per year;

- Identification of specific frequent or relevant issues classified according to: (a) visual data recording technologies, (b) other associated technologies, and (c) other topics, including construction typology, integration of visual technologies with 
construction management systems, the analysis of the costs involved in adopting the technologies and the literature review articles.

\section{LITERATURE REVIEW 2: USE OF UAVS TO AID PROGRESS MONITORING}

For this search, the following combination of terms was used: Construction "progress monitoring" and UAV or UAS. Due to the relatively small number of papers initially found (13), the restrictions considered in the previous search (year and journal) were not performed. Only a paper selection was done by general reading, trying to remove works in which the UAV was only cited, but its use or application were not presented and discussed. The structure, with the steps adopted for this literature search, is presented in Figure 2.

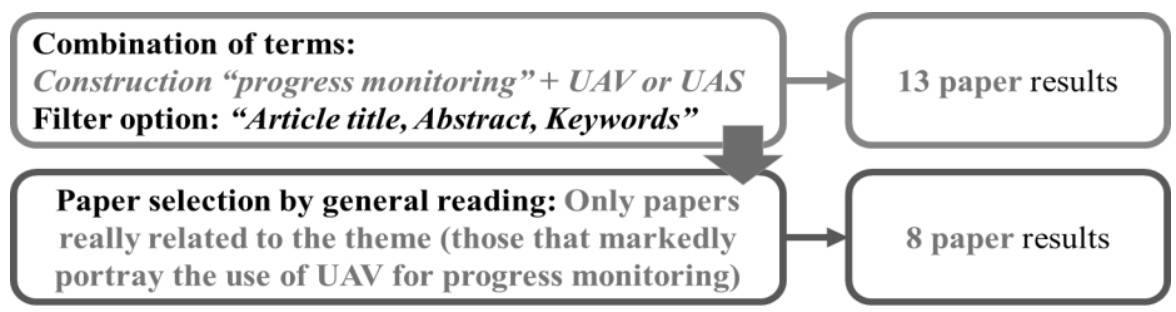

Figure 2:Step-by-step of the literature search 2

The same analyses previously described were performed for the eight selected papers. However, in addition to the identification, the discussions on how the studies deal with the main frequent or relevant issues and how the papers address the specific use of UAVs were also developed.

\section{RESULTS AND DISCUSSION}

This section presents the main results obtained with both the literature reviews performed.

\section{USE OF VISUAL DATA FOR CONSTRUCTION PROGRESS MONITORING}

As shown in Table1, among the 22 papers selected, the journal with the largest amount was Automation in Construction, with a total of nine papers (40.9\% of the sample), followed by the Journal of Computing in Civil Engineering with five papers (22.7\%), Journal of Information Technology in Construction with two papers (9.1\%), and six other journals, all with one paper each (4.5\% each).

The great majority of these journals is focused on subjects related to the use of technologies in construction. The journal with the largest number of papers has the second largest Impact Factor of the sample (2.919), which is a very significant when compared to the values of the journals in this knowledge area. Thus, the use of visual data to progress monitoring seems to have a considerable impact regarding the technologies applied to construction. 
Table 1: Distribution of the number of papers per year and sources of publication (Literature review 1)

\begin{tabular}{|c|c|c|c|c|c|c|c|c|c|c|c|c|c|}
\hline \multirow{2}{*}{ Paper Source } & \multirow{2}{*}{$\begin{array}{l}\text { Impact } \\
\text { Factor }\end{array}$} & \multicolumn{11}{|c|}{ Distribution of papers per year $\left(20 \_\right)$} & \multirow{2}{*}{ Total } \\
\hline & & 08 & 09 & 10 & 11 & 12 & 13 & 14 & 15 & 16 & 17 & 18 & \\
\hline Automation in Construction & 2.919 & & & 1 & 2 & 1 & 1 & & 1 & 1 & 1 & 1 & 9 \\
\hline $\begin{array}{l}\text { Journal of Computing in Civil } \\
\text { Engineering }\end{array}$ & 2.310 & & 1 & & & & 2 & & 1 & 1 & & & 5 \\
\hline $\begin{array}{l}\text { Journal of Information } \\
\text { Technology in Construction }\end{array}$ & - & & 1 & & & & & & 1 & & & & 2 \\
\hline ACM Transactions on Graphics & 4.088 & & & & & & & 1 & & & & & 1 \\
\hline $\begin{array}{l}\text { Advanced Engineering } \\
\text { Informatics }\end{array}$ & 2.680 & & & & & & & & 1 & & & & 1 \\
\hline $\begin{array}{l}\text { Journal of Management in } \\
\text { Engineering }\end{array}$ & 2.011 & & & & & & & & & 1 & & & 1 \\
\hline $\begin{array}{l}\text { Journal of Construction } \\
\text { Engineering and Management }\end{array}$ & 1.735 & & & & & & & & & & & 1 & 1 \\
\hline $\begin{array}{l}\text { Photo grammetrie } \\
\text { Fernerkundung Geo } \\
\text { information }\end{array}$ & 0.852 & & & & & & & & & & 1 & & 1 \\
\hline $\begin{array}{l}\text { Canadian Journal of Civil } \\
\text { Engineering }\end{array}$ & 0.591 & 1 & & & & & & & & & & & 1 \\
\hline \multicolumn{2}{|l|}{$\begin{array}{r}\text { Total } \\
\end{array}$} & 1 & 2 & 1 & 2 & 1 & 3 & 1 & 4 & 3 & 2 & 2 & 22 \\
\hline
\end{tabular}

Regarding the distribution over the last years of publications (Table 1), there is a certain variation related to the quantity of papers from year to year. The higher concentration occurred between 2013 and 2016 (despite the decrease in 2014), with the peak of four papers in 2015. Another highlight is the presence of two papers already in 2018, in which such data was measured at the beginning of March 2018.

The most frequent or relevant subjects among the papers identified in this literature review were divided into three main categories: (a) visual data recording technologies, (b) other associated technologies, and (c) other topics addressed. The frequencies for the items considered in each of these categories are presented in the graphs of Figure 3.
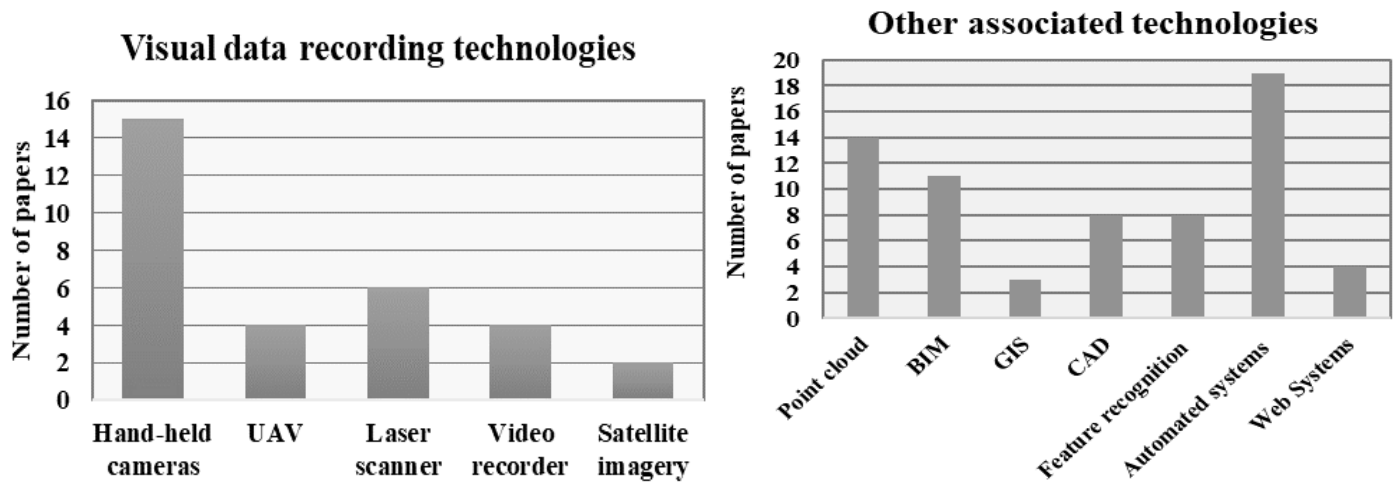


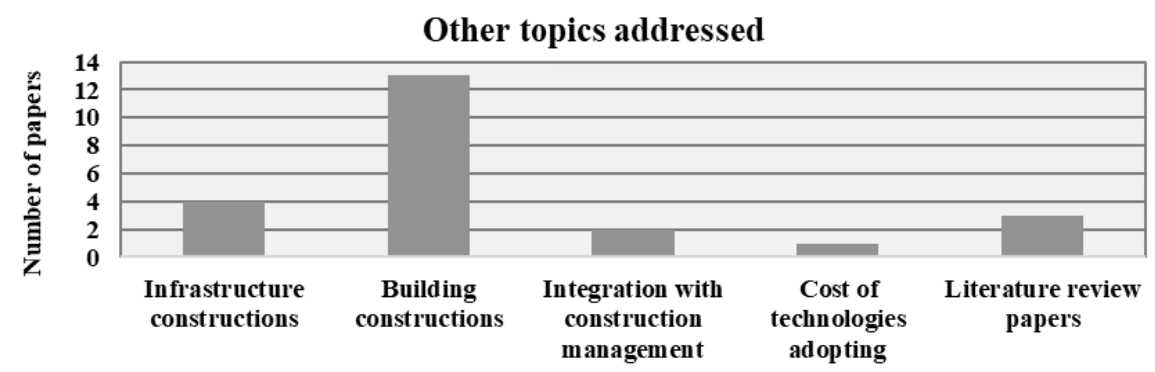

Figure 3: Frequencies of the most frequent or relevant subjects in the 22 papers, according to three main categories

For the category of technologies for visual data recording in sites (Figure 3), a major highlight is the acquisition of images by hand-held digital cameras, presented in 15 of the 22 papers, since the maximum obtained for another technology type was six papers (Laser scanner). This represents a predominance of digital photographs as the main type of visual data to record work status used for progress monitoring.

Regarding other types of associated technologies (Figure 3), the use of automated systems is noteworthy, appearing in 19 of the 22 papers. Examples of these types of systems include automated image processing techniques, and computer systems for progress monitoring by automating the superimposition of visual as-built and as-planed representations (using 4D BIM, for example). In addition, there is a relative frequency of $3 \mathrm{D}$ as-built by point cloud technologies (present in 14 of the 22 papers) and as-planned BIM (in 11 of the 22 papers), often presented in a comparative approach, as a way of identifying deviations between what was planned and constructed.

Among the papers selected, the predominance of the use of visual technologies for building construction monitoring (in 13 papers), compared to infrastructure construction (in only four papers) (Figure 3) was noted. The topic concerned with the integration of visual progress monitoring to the construction management system presented very low frequency among the papers and was addressed directly by only two of the 22 (Figure 3 ). However, it can be considered as an important and relevant topic when analysing this subject from a managerial point of view, since progress monitoring is an important activity in production control, which must be part of the site management routine as well as being systematic. Moreover, these two papers were written practically by the same authors, who present an identical approach (the same idea of managerial workflow) in both papers.

\section{USE OF UAVS TO AIDPROGRESS MONITORING}

Due to the reduced number of publications in journals that specifically addressed the use of UAVs for visual data collection for construction progress monitoring (only four papers),this second literature search also considered the publications in conferences proceedings, representing a still relatively small amount of studies. Table 2 shows the distribution of the eight papers selected according to the source and year of publication. 
Table 2: Distribution of the number of papers per year and source of publication (Literature review 2)

\begin{tabular}{l|c|c|c|c|c|c}
\hline \multirow{2}{*}{ Paper Source } & \multirow{2}{*}{ Impact } & \multicolumn{3}{c|}{ Distribution of papers per year } & \multirow{2}{*}{ Total } \\
\cline { 3 - 7 } & Factor & $\mathbf{2 0 1 5}$ & $\mathbf{2 0 1 6}$ & $\mathbf{2 0 1 7}$ & $\mathbf{2 0 1 8}$ & \\
\hline Automation in Construction & 2.919 & - & - & 1 & - & 1 \\
Journal of Management in Engineering & 2.011 & - & 1 & - & - & 1 \\
$\begin{array}{l}\text { Journal of Construction Engineering and } \\
\text { Management }\end{array}$ & 1.735 & - & - & - & 1 & 1 \\
$\begin{array}{l}\text { Photogrammetrie Fernerkundung } \\
\text { Geoinformation }\end{array}$ & 0.852 & - & - & 1 & - & 1 \\
Conference proceedings & & & & & & \\
\hline \multicolumn{1}{c}{ Total } & - & 1 & 1 & 2 & - & 4 \\
\hline
\end{tabular}

According to the Table 2data, the publications have been found since 2015, with an apparent increase over time (one paper from 2015, two from 2016, four from 2017 and another one already from 2018).These results might show a relatively recent, but growing, state of research that addresses UAV as a visual data capture tool for progress monitoring. Thus, consequently, this topic probably still has fields to be explored by future works.

Table 3presents the main recurrent or relevant specific subjects addressed by the eight papers, as well as how these studies approach such issues, following the classification of the three major categories and organization of items similar to those presented previously.

\section{Other Technologies for Recording Visual Data}

Other visual data recording technologies include digital cameras for image recording, video recording and laser scanning for point clouds generation (Table 3). Han et al. (2018), Tuttas et al. (2017) and Han and Golparvar-Fard (2017) present the hand-held camera as a source for images used in image-based point cloud model generation, as a representation of the as-built status. Tuttas et al. (2017) make a comparison between UAVs and hand-held cameras, showing that UAVs were more successful in providing images from different angles and heights, allowing for complete coverage of the site and guaranteeing great overlap between images (fundamental criterion for good quality photogrammetric processing).

Regarding video recording, Han and Golparvar-Fard (2017) commented that this is also a good alternative for construction monitoring purposes, since it allows for the visualization of work in progress. However, the use of the laser scanners, although more expensive, with more limited mobility and positioning compared to image registration, allows for the generation of point clouds with less noise and generally denser (Han et al., 2018; Tuttas et al., 2017; Han and Golparvar-Fard, 2017). 
Table 3: Most frequent or relevant subjects covered by the papers

\begin{tabular}{|c|c|c|c|c|c|c|c|c|c|c|c|}
\hline \multirow{2}{*}{\multicolumn{3}{|c|}{$\begin{array}{c}\text { Most frequent or relevant subjects in the } 8 \\
\text { selected papers }\end{array}$}} & \multicolumn{8}{|c|}{ Subjects of each paper } & \multirow{2}{*}{ Total } \\
\hline & & & A1 & A2 & A3 & A4 & A5 & A6 & \multirow[t]{5}{*}{ A7 } & \multirow[t]{5}{*}{ A8 } & \\
\hline \multirow{4}{*}{\multicolumn{2}{|c|}{ 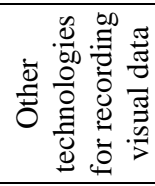 }} & Images by hand-held digital cameras & \multirow{4}{*}{$\begin{array}{l}\mathrm{x} \\
\mathrm{x}\end{array}$} & \multirow{4}{*}{$\begin{array}{l}\mathrm{X} \\
\mathrm{X}\end{array}$} & & & \multirow{4}{*}{$\begin{array}{l}x \\
x \\
x\end{array}$} & \multirow{4}{*}{$\mathrm{x}$} & & & 3 \\
\hline & & Laser scanner & & & & & & & & & 3 \\
\hline & & Video recorder & & & & & & & & & 2 \\
\hline & & Satellite imagery & & & & & & & & & 0 \\
\hline \multirow{7}{*}{\multicolumn{2}{|c|}{ 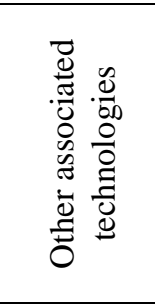 }} & Point cloud (digital photogrammetry) & \multirow{4}{*}{$\begin{array}{l}\mathrm{X} \\
\mathrm{X}\end{array}$} & \multirow{5}{*}{$\begin{array}{l}\mathrm{X} \\
\mathrm{X}\end{array}$} & \multirow{5}{*}{$\begin{array}{l}\mathrm{X} \\
\mathrm{X}\end{array}$} & \multirow{5}{*}{$\mathrm{x}$} & \multirow{4}{*}{$\begin{array}{l}\mathrm{X} \\
\mathrm{X}\end{array}$} & & \multirow[t]{4}{*}{$\mathrm{x}$} & \multirow{4}{*}{$\begin{array}{l}\mathrm{x} \\
\mathrm{x}\end{array}$} & 6 \\
\hline & & Building Information Modeling (BIM) & & & & & & & & & 6 \\
\hline & & Geographic Information System (GIS) & & & & & & & & & 0 \\
\hline & & Computer-Aided Design (CAD) & & & & & & & & & 0 \\
\hline & & Feature/pattern recognition techniques & \multirow{3}{*}{$\begin{array}{l}\mathrm{X} \\
\mathrm{X}\end{array}$} & & & & \multirow{3}{*}{\multicolumn{2}{|c|}{$\begin{array}{l}X \\
X \\
X\end{array}$}} & \multirow{3}{*}{$\begin{array}{l}\mathrm{x} \\
\mathrm{x}\end{array}$} & \multirow{3}{*}{$\begin{array}{l}\mathrm{X} \\
\mathrm{X}\end{array}$} & 4 \\
\hline & & Automated systems technologies & & \multirow[t]{2}{*}{$\mathrm{x}$} & \multirow[t]{2}{*}{$\mathrm{x}$} & \multirow{2}{*}{$\begin{array}{l}\mathrm{X} \\
\mathrm{X}\end{array}$} & & & & & 7 \\
\hline & & Web Systems & & & & & & & & & 2 \\
\hline \multirow{4}{*}{ 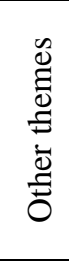 } & \multirow{2}{*}{$\begin{array}{l}\overrightarrow{30} \\
\stackrel{0}{0} \\
\stackrel{2}{\circ} \\
\stackrel{2}{\lambda}\end{array}$} & Building constructions & \multirow[t]{2}{*}{$\mathrm{x}$} & \multirow[t]{2}{*}{$\mathrm{x}$} & \multirow[t]{2}{*}{$\mathrm{x}$} & & \multirow[t]{2}{*}{$\mathrm{x}$} & \multirow[t]{2}{*}{$\mathrm{x}$} & & \multirow[t]{2}{*}{$\mathrm{x}$} & 6 \\
\hline & & Infrastructure constructions & & & & & & & & & 0 \\
\hline & \multicolumn{2}{|c|}{$\begin{array}{l}\text { Integration with construction management } \\
\text { Cost of technologies adopting }\end{array}$} & \multirow[t]{2}{*}{$\mathrm{X}$} & & & & $\mathrm{x}$ & $\mathrm{X}$ & & & $\begin{array}{l}2 \\
1\end{array}$ \\
\hline & Litera & ture review papers & & & & $\mathrm{x}$ & $\mathrm{X}$ & & & & 2 \\
\hline
\end{tabular}

Most discussed subjects; $\square$ Less discussed subjects;

Subjects not covered

A1: Han et al. (2018); A2: Tuttas et al.(2017); A3: Qu et al. (2017); A4: McCabe et al. (2017); A5: Han and Golparvar-Fard (2017); A6: Irizarry e Costa (2016); A7: Fang et al.(2016); A8: Lin et al. (2015).

\section{Other Associated Technologies}

For this category, as in the first search, automated systems technologies were more prominent addressed(in seven of the eight papers - Table 3), which include: systems for UAV automatic control (McCabe et al., 2017; Han and Golparvar-Fard, 2017; Lin et al., 2015);automated photogrammetric processing for point cloud generation(Structure-fromMotion - SfM) (Han et al., 2018; Tuttas et al., 2017; Qu et al., 2017; Han and GolparvarFard, 2017; Fang et al., 2016; Lin et al., 2015);automatic object detection by identifying the BIM elements' geometry present in the point cloud model(Han and Golparvar-Fard, 2017), and the use of this for point cloud automatic filtering (Han et al., 2018); automated appearance-based material classification technique (Han et al., 2018; Lin et al., 2015); and semiautomatic moving object detection (Fang et al., 2016).

Technologies such as point cloud by digital photogrammetry and Building Information Modelling (BIM) are also addressed in most papers (both in six of eight papers). In the works that address BIM, this is treated as the main visual representation of as-planned (4D BIM), used as a comparative basis for visual evaluation and communication of deviations from planed construction progress.

\section{Other Themes}

The most important construction typology among the studies (presented in case studies or field tests) are building construction (in six of the eight papers - Table 3), and no study that dealt with infrastructure works was observed. 
One of the most relevant subjects among those addressed by the papers was the systematic integration of the UAV-supported visual monitoring systems with construction management. However, only two papers dealt directly with this approach, and were the same studies mentioned in the previous literature review.

In their study, Han and Golparvar-Fard (2017) point out that the construction sites recording by images and videos, along with as-planned4D BIM, provide good opportunities for detection, analysis and communication of construction performance among project teams, and can thus serve as support to daily execution activities and short-term planning. Therefore, the authors present a continuous workflow cycle between short-term planning and daily work control based on visual data, as shown in Figure 4.

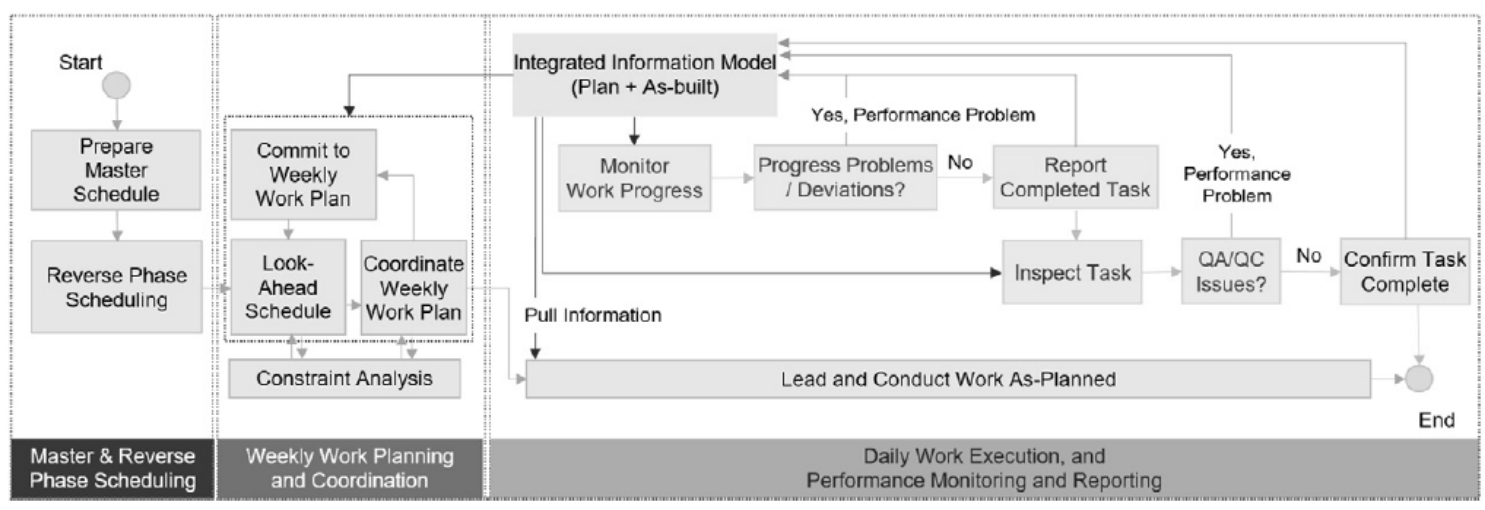

Figure4: Example workflow of the integration of visual data into the construction management system (Figure 1 in Han and Golparvar-Fard, 2017 and in Han et al., 2018)

The other study which also deals with this topic (Han et al., 2018), presents the same workflow as Han and Golparvar-Fard (2017) (Figure 4), with direct citation of this work. Han et al. (2018) emphasize that these visual systems for progress monitoring, according to the workflow presented, allow for more effective production control by almost realtime automated evaluations of the work on site, aiding project teams in maintaining a continuous flow of information and production.

Another relevant aspect was the issue of the costs involved in adopting the technology. Irizarry and Costa (2016) comment that these costs include the necessary authorizations for UAV operation (depending on the country's regulations), the equipment itself, operators' training or outsourced service contracting to operate the UAV, as well as insurance.

\section{The UAV as a tool for Construction Progress Monitoring}

The specific approach of the UAV technology for progress monitoring varied slightly among the eight selected papers. Five studies (Han et al., 2018; Tuttas et al., 2017; Quet al., 2017; Han and Golparvar-Fard, 2017; Linet al., 2015) approach the UAV as a tool for continuous acquisition of site images, used for point cloud model generation, that visually represent the construction evolution (different phases and changes). In all of these five papers, the point cloud models (as-built representation) are used in comparison with 4D 
BIM (as-planed work evolution representation), aiming to analyse the construction performance, identifying progress deviations.

For the other three papers, Fang et al. (2016) present UAVs as an alternative for recording images used in the continuous 3D tracking of the construction elements(e.g. workers, equipment, materials), for applications that include progress monitoring. Irizarry and Costa (2016) also identify progress monitoring as one of the potential managerial applications for UAVs' visual assets of the site (photos and videos). McCabe et al. (2017) provide a literature review of the potential of UAVs for internal building monitoring.

In general, among the eight papers, the main advantages of using UAVs are their ability to provide high-quality images, recorded from different angles and heights, covering the entire construction site in a quick, economical, and efficient way. However, some limitations are also considered, such as safety issues related to care of tall structures proximity, potential safety hazards to workers for possible distractions, flight limitations imposed by regulations, and the limited flight time due to battery capacity.

\section{CONCLUSIONS}

This study presented a systematic literature review and general analysis of scientific papers that discuss the use of the Unmanned Aerial Vehicle (UAV) as a tool to support construction progress monitoring. As a principal contribution, this paper sought to present the current state of the topic, taking into account the main recurrent specific issues among the papers, or those that still need to be explored, as well as to discuss how the papers address the issue of the use of UAVs specifically.

The literature review performed indicates the use and principally the development of automated system technologies as the subject most overly addressed in the studies related to visual progress monitoring. These systems are often presented as being able to improve the progress control process, making it faster, more automated and efficient. In addition, the use of point cloud models for as-built 3D representation and BIM for as-planned are presented as the main visual technologies to aid construction progress monitoring.

However, although the studies searched highlight the potential of visual technologies for progress monitoring improvement, including some of these studies which even mentioned the improvement of production aspects associated to Lean principles, such as increased transparency and collaboration, and non-value adding activities reduction, a gap was identified regarding the lack of studies that effectively integrate the visual monitoring with the construction management systems. Only two papers directly address this subject, showing that there is still low emphasis and frequency in the literature about this topic.

Thus, important issues associated with such a subject still need to be explored more in the studies that address visual progress monitoring, especially with the support of UAVs. Among these, there is a need to propose, apply and evaluate an integrated management system of collecting, processing, analysing and decision making in terms of deviations in construction progress, and also associated with the implementation of corrective actions. It is also necessary to evaluate the impact of this new flow of information within the construction management system, considering aspects associated with Lean principals, such as improvement of visual management, increased communication and collaboration 
in construction progress management, better compliance with the goals set in the planning and deadlines, increased process transparency, non-value adding activities reduction and maintenance of continuous flow of production.

\section{REFERENCES}

Ballard, H. G. (2000) "The Last Planner System of Production Control". Thesis, Faculty of Engineering, The University of Birmingham, Birmingham.

Del Pico, W. J. (Ed.). (2013) Project Control: Integrating Cost and Schedule in Construction. Hoboken: John Wiley \& Sons, Inc.

Elsevier. (2016) "Scopus: Content Coverage Guide". Elsevier B.V.

Fang, Y., Chen, J., Cho, Y. K. and Zhang, P. (2016) "A Point Cloud-Vision Hybrid Approach for 3D Location Tracking of Mobile Construction Assets". Proc. of International Symposium on Automation and Robotics in Construction (ISARC), 33.

Golparvar-Fard, M., Peña-Mora, F. and Savarese, S (2009) "Application of D4AR - A 4Dimensional augmented reality model for automating construction progress monitoring data collection, processing and communication". Journal of Information Technology in Construction (ITcon), 14, 129-153.

Han, K. K. and Golparvar-Fard, M. (2015) "The role of integrated plan and as-built models in achieving smooth flow of production in construction". Proc. of Int. Conference on Innovative Production and Construction (IPC 2015), Perth, 101-104.

Han, K. K. and Golparvar-Fard, M. (2017) "Potential of big visual data and building information modelling for construction performance analytics: An exploratory study". Automation in Construction, 73, 184-198.

Han, K. K., Degol, J. and Golparvar-Fard, M. (2018) "Geometry- and Appearance-Based Reasoning of Construction Progress Monitoring". Journal of Construction Engineering and Management, 144(2): 04017110.

Irizarry, J. and Costa, D. B. (2016) "Exploratory Study of Potential Applications of Unmanned Aerial Systems for Construction Management Tasks". Journal of Management in Engineering, 32.

Lin, J. J. and Golparvar-Fard, M. (2017) "Proactive Construction Project Controls via Predictive Visual Data Analytics". Proc. of Computing in Civil Engineering, 147-154.

Lin, J. J., Han, K. K. and Golparvar-Fard, M. (2015) "A Framework for Model-Driven Acquisition and Analytics of Visual Data Using UAVs for Automated Construction Progress Monitoring”. Proc. of Computing in Civil Engineering, 156-164.

McCabe, B. Y., Hamledari, H., Shahi, A., Zangeneh, P. and Rezazadeh Azar, E. (2017) "Roles, Benefits, and Challenges of Using UAVs for Indoor Smart Construction Applications". Proc. of Computing in Civil Engineering, 349-357.

Qu, T., Zang, W., Peng, Z., Liu, J., Li, W., Zhu, Y., Zhang, B. and Wang, Y. (2017) "Construction site monitoring using UAV oblique photogrammetry and BIM technologies". Proc. of International Conference of the Association for ComputerAided Architectural Design Research in Asia (CAADRIA), Hong Kong, 22, 655-662.

Sacks, R., Koskela, L., Dave, B. A. and Owen, R. (2010) "Interaction of Lean and Building Information Modelling in Construction". Journal of Construction Engineering and Management, 136, 968-980. 
Juliana S. Álvares, and Dayana B. Costa

Teizer, J. (2015) "Status quo and open challenges in vision-based sensing and tracking of temporary resources on infrastructure construction sites". Advanced Engineering Informatics, 29, 225-238.

Tezel, A. and Aziz, Z. (2017) "From Conventional to IT Based Visual Management: A Conceptual Discussion for Lean Construction". Journal of Information Technology in Construction (ITcon), 22, 220-246.

Tuttas, S., Braun, A., Borrmann, A. and Stilla, U. (2017) "Acquisition and Consecutive Registration of Photogrammetric Point Clouds for Construction Progress Monitoring Using a 4D BIM". Photogrammetrie, Fernerkundung, Geoinformation, 85, 3-15. 